\title{
ATIVIDADES COMPLEMENTARES CURRICULARES (ACCS) COMO POĹTICA EDUCACIONAL NO ESTADO dO PARANÁ
}

\author{
COMPLEMENTARY ACTIVITIES OF THE CURRICULUM (ACCS) AS EDUCATION POLICY \\ IN THE STATE OF PARANÁ \\ ACTIVIDADES COMPLEMENTARES DEL CURRÍCULO (ACCs) COMO POLÍTICA DE \\ EDUCACIÓN EN EL ESTADO DE PARANÁ
}

\section{Eduard Angelo Bendrath ${ }^{1}$ Andréia Paula Basei ${ }^{2}$}

RESUMO: O objetivo desse trabalho foi compreender o perfil da política de Atividades Complementares Curriculares (ACCs) do Estado do Paraná. O estudo caracteriza-se como uma pesquisa de levantamento com informações provenientes de bancos de dados oficiais do Ministério da Educação (MEC) sendo o $\mathrm{N}$ amostral composto por 372 escolas de 19 cidades. As informações sobre as ACCs foram cruzadas com os demais indicadores escolares para a composição dos resultados. Constatou-se que há uma tendência de adesão superior a $80 \%$ das escolas a essa política e que a participação dos alunos nos projetos desenvolvidos está em fase de expansão, no entanto, não foi possível observar relação entre melhoria de indicadores de qualidade educacional com maior participação nas ACCs.

PALAVRAS-CHAVE: Política educacional. Atividades complementares curriculares. Ampliação do tempo escolar.

ABSTRACT: The objective of this study was to understand the profile of complementary activities of the Curriculum (ACCs) of Paraná State. We opted for a study with information from databases of the Ministry of Education (MEC) and the sample composed of 372 schools in 19 cities. The information on the ACCs were crossed with the other indicators for the composition of the results. It was noted that there is a tendency for membership of more than $80 \%$ of schools to this policy, and that the participation of pupils in projects developed is in the expansion phase, however, it was not possible to detect a relation between improvement of indicators of educational quality with greater participation in the ACCs.

KEYWORDS: Education policy. Complementary activities curricular. Expansion of the school time.

RESUMÉN: El objetivo de este estudio fue comprender el perfil de actividades complementares del currículo (ACCs) del estado de Paraná. Hemos optado por un estudio con información procedente de bases de datos del Ministerio de Educación (MEC) y la muestra compuesta de 372 escuelas en 19 ciudades. La información de la ACCs se cruzaron con los demás indicadores de la composición de los resultados. Se observó que existe una tendencia de aceptación de más de $80 \%$ de las escuelas a esta política, y que la participación de los alumnos en proyectos desarrollados hace en fase de expansión, sin embargo, no fue posible detectar una relación entre la mejora de los indicadores de la calidad de la enseñanza, con una mayor participación en la ACCs.

PALABRAS ClAVE: Política de educación. Actividades complementares del currículo. Ampliación de lo tiempo escolar.

Submetido em: 25/09/2017 - Aceito em: 25/10/2017 - Publicado em: 27/03/2018.

\begin{tabular}{l|c|c|c|c|c|c|} 
(C) Rev. Educ. Perspec. & Viçosa, $M G$ & v.9 & n.1 & p.104-126 & jan./abr. 2018 & eISSN 2178-8359 \\
\hline
\end{tabular}




\section{INTRODUÇÃO}

A inserção de atividades complementares curriculares (ACCs) nas escolas públicas vem crescendo gradativamente em todo o país e sua justificativa pauta-se em aspectos diversos que vão desde a ampliação do tempo da jornada escolar, passando pelo círculo da socialização, melhoria da qualidade educacional, até aspectos voltados para o mercado de trabalho e a ampliação do processo de formação do capital humano.

Segundo Ferreira e Rees (2015), a educação brasileira vem se modificando ao longo dos anos na tentativa de acompanhar as constantes mudanças econômicas, políticas e sociais pelas quais a sociedade vem passando. No Estado do Paraná, o governo vem desde o ano de 2011 através da Resolução n. 1.690 atuando para consolidar este programa de atividades complementares curriculares nas escolas estaduais. De acordo com o documento, o objetivo do programa visa a melhoria da qualidade do ensino por meio da ampliação de tempos, espaços e oportunidades educativas realizadas na escola em contraturno, a fim de atender as demandas socioeducativas dos alunos.

De acordo com Cavaliere (2016) as propostas de ampliação do tempo em que os alunos ficam sob a responsabilidade da escola são desenvolvidas a partir de conceitos que, de modo geral, associam novas responsabilidades, atividades, agentes e espaços à vida escolar e novas relações desta com a localidade e outras instituições sociais.

Nesse sentido, como finalidade direta da política pública, a Instrução normativa 07/2012 da Secretaria de Educação do Paraná (SEED/PR) (PARANÁ, 2012) indica que uma das metas é oportunizar a expansão do tempo escolar para alunos da educação básica da rede pública estadual de ensino como forma indutora para a progressiva implantação da educação em tempo integral. É nesse novo paradigma social que o discurso de educar integralmente, de preparar os educandos, física, afetiva, cultural e cognitivamente ganha força e atinge todos os âmbitos da esfera política, concretizando-se nos documentos oficiais que regulamentam a educação no País (FERREIRA; REES, 2015).

A partir de tal perspectiva, observa-se uma tendência de reforma educacional velada da educação pública paranaense, onde pese a progressão para a ampliação da jornada (tempo) escolar e a utilização do programa de ACCs como teste para ajuste de logística e de desempenho escolar em determinado espaço de tempo. Compreende-se tal processo como movimento reformista quando observa-se que, gradativamente, haverá alterações na estrutura de trabalho docente (GARCIA; ANADON, 2009), bem como impactos nas dimensões políticas, técnicas e financeiras das escolas (KRAWCZYK, 2002). 
De acordo com Belloni, Magalhães e Sousa (2007), uma política pública desempenha distintos papéis, dependendo do setor/grupo social ao qual se destina e do tipo de relação que estabelece com as demais políticas. Para os autores a compreensão de como a política pública se comporta frente aos objetivos e metas confere a possibilidade de correção de problemas que resultem em ineficiência e perda de recursos públicos.

Dessa forma, o objetivo desse trabalho foi traçar um macro perfil das ACCs em 372 escolas em cidades com mais de 100.000 habitantes localizadas no interior do Estado do Paraná, observando-as a partir da perspectiva de uma eventual reforma com vistas para ampliação gradativa do tempo da jornada escolar. Compreender a estrutura macro de uma política de ampliação de oportunidades educativas favorece a observação de potencialidades, limites, convergências e divergências ao qual o investimento de recursos públicos se faz necessário.

A presente pesquisa é resultado de esforços que visam compreender a dinâmica de ações educacionais complementares nas escolas estaduais do Paraná e recebeu recursos financeiros do Conselho Nacional de Desenvolvimento Científico e Tecnológico (CNPq) por meio do processo 401984/2016-8.

\section{PLANEJAMENTO E REFORMAS ESTRUTURAIS PARA OFERTA EDUCACIONAL}

De acordo com a Unesco (2016, p. 8) "as mudanças no mundo, atualmente, se caracterizam por novos níveis de complexidade e contradição. A educação deve preparar indivíduos e comunidades para as tensões geradas por tais mudanças, tornando-os capazes de se adaptar e de responder a elas".

A capacidade de adaptação dos indivíduos às constantes mudanças e a garantia de uma formação plena e emancipatória são colocadas, portanto, em cheque na escola pública. Isoladamente, a educação não pode esperar resolver todos os desafios relacionados ao desenvolvimento, seu objetivo significa ir além da estreita visão utilitarista e economicista, buscando integrar as múltiplas dimensões da existência humana (UNESCO, 2016). A ampliação das oportunidades educativas caminha nesse sentido.

Com essa perspectiva, a participação de organismos internacionais no delineamento de uma posição de consenso internacional sobre determinados temas, dentre eles a educação, conferiu ao Estado, a função de executor de programas e medidas de origem transnacional para salvaguardar a macroeconomia e assegurar o desenvolvimento dentro do modelo capitalista (BENDRATH; GOMES, 2010). Segundo os autores, por meio de tais proposições, os modelos de políticas públicas adotados pelos organismos internacionais tenderiam a 
favorecer movimentos educacionais que fogem da rigidez e burocracia estatal, ampliando o acesso da sociedade a projetos pontuais.

Assim, o que se observa na política pública educacional do Estado do Paraná é o princípio de uma reforma educacional com vistas a ampliar a jornada escolar de forma gradual, até que todos os parâmetros mínimos que compreendem a definição de escolas de tempo integral sejam cumpridos e ofertados a todos os alunos da rede pública estadual. O acesso à educação de tempo integral, nesse caso, segue um fluxo baseado em projetos de contraturno, cujos objetivos seriam definidos pela comunidade escolar local. Outro aspecto destacado na Res. n. 1.690/2011 e Instrução SEED 07/2012 diz respeito a utilização da política de ACCs como forma de garantir a melhoria da qualidade de educação por meio da ampliação de tempos, espaços e oportunidades educativas com prioridade para alunos em situação de vulnerabilidade social.

Tais prerrogativas se adequam aos postulados de organismos internacionais, em especial à UNESCO, que fomenta a consolidação de políticas educacionais baseadas em consenso internacional e difundidas via marcos e orientações aos seus países membros. A definição da organização para o "marco do milênio 2015" trazia, dentre outras orientações uma expressa recomendação de estender a educação integral para crianças e jovens em situações de vulnerabilidade (UNESCO, 2007).

Campos (2013) destaca que as orientações de organismos internacionais não podem ser compreendidas como ações diretas e impositivas, sendo que países diferentes interpretarão o conjunto de recomendações de maneiras distintas baseados nas suas tradições de política social e educativa. Segundo o autor, a partir dos anos 1990 a UNESCO passa a recomendar estratégias educativas para o Brasil voltadas para políticas focais, em que o princípio da competitividade é substituído gradativamente pelo conceito de equidade.

A influência de organismos internacionais no delineamento de políticas educacionais no Brasil não é novidade e perpassa pelos interesses da agenda global e suas adequações a partir de cada momento histórico. De acordo com Altmann (2002), a influência exercida pelo Banco Mundial na política educacional brasileira é reflexo das ingerências no setor macroeconômico ocorrido nos anos 1990 e tinham como foco o aumento da competitividade nacional a partir de uma educação otimizada para ampliação do capital humano.

Em relação ao papel da UNESCO no cenário nacional, seu principal eixo de ação esteve na elaboração e implantação, em parceria com a Secretaria Estadual de Educação de São Paulo, no início dos anos 2000, do Programa Escola da Família. Programa que chegou a estar presente em 6.000 escolas estaduais, oferecendo atividades vinculadas a projetos temáticos

\begin{tabular}{l|c|c|c|c|c|c|}
\hline () Rev. Educ. Perspec. & Viçosa, $M G$ & v.9 & n.1 & p.104-126 & jan./abr. 2018 & eISSN 2178-8359 \\
\hline
\end{tabular}


em eixos como cultura, esporte, trabalho e saúde, atuando de forma paralela e complementar ao sistema formal de ensino (BENDRATH, 2010).

Esse modelo de política focada em projetos de interesse local das comunidades atraiu interesse de diversos governos, dentre eles, do governo federal que o lançou com o nome de "Programa Abrindo Espaços", do governo do Rio de Janeiro com o nome de "Programa Escola de Paz", do governo de Pernambuco com o nome definido de "Programa Escola Aberta Cultura de Paz e Lazer nas Escolas aos Finais de Semana", e do governo da Bahia cujo nome escolhido foi "Programa Abrindo Espaços: Educação e Cultura para a Paz" (BENDRATH, 2012). Ainda segundo o autor, nos últimos anos, o Brasil vem observando o crescente interesse desses organismos na implantação e gerenciamento de ações e políticas públicas em parceria com a União, Estados e Municípios.

Em que pese a não diretividade impositiva e os ajustes pontuais às orientações de organismos internacionais tal qual observado por Campos (2013), é fato concreto que a base de planejamento e estruturação educacional dos governos (Federal, Estaduais e Municipais) sofre direta influência dos padrões, metas, e parâmetros difundidos por esses mesmos organismos.

Para Libâneo (2016), a UNESCO e o Banco Mundial exercem papel significativo no delineamento de políticas públicas no Brasil. Para o autor são políticas intencionalmente dirigidas ao atendimento à diversidade social e, de algum modo, compondo as estratégias de educação direcionada para alívio da pobreza. Ainda de acordo com Libâneo (2016), a proposta de educação integral, com ampliação da jornada escolar, parte do entendimento de que a escola precisa mudar seu papel convencional, assumindo outras funções não tipicamente escolares, ou seja, as funções de educadora e protetora.

Dessa forma, a educação integral é vista "como um processo que abrange as múltiplas dimensões formativas do aluno, cujo objetivo é a formação integral numa jornada ampliada por meio da oferta de atividades diversificadas articuladas com o projeto pedagógico" (BRASIL, 2009, p. 18).

A implantação de uma escola de tempo integral, com base nos princípios da oferta de uma educação de qualidade, requer o entendimento de uma mudança do status quo do panorama educacional atualmente em vigor. Os postulados de uma reforma, mesmo que limitada e baseada em fatores pontuais, parece ser a estratégia adotada por diversos governos (dentre eles o governo do Paraná) para a obtenção de seus objetivos em curto e médio prazo.

Assim, a adequação de jornada de trabalho docente com consequente impacto orçamentário, permanência estudantil com garantia de alimentação e espaço físico adequado, insumos para

\begin{tabular}{l|l|l|l|l|l|l} 
() Rev. Educ. Perspec. & Viçosa, $M G$ & v.9 & n.1 & p.104-126 & jan./abr. 2018 & eISSN 2178-8359 \\
\hline
\end{tabular}


a execução de projetos específicos, bem como uma reconfiguração do projeto pedagógico que esteja alinhado com os objetivos educativos da educação básica associado aos anseios e necessidades de um modelo educativo complementar, são apenas alguns elementos que devem ser observados a partir da perspectiva de implantação de um modelo de educação em tempo integral. De acordo com a UNESCO (2016), os níveis cada vez maiores de complexidade social e econômica apresentam vários desafios para a formulação de políticas educacionais.

A política de ACCs em vigor no Estado do Paraná trata-se de um modelo de teste (em que pese sua limitação), que visa aferir o comportamento e o cotidiano escolar face a uma reconfiguração da escola pública. Para tal compreensão desse panorama Carnoy (2002), traça três possibilidades usualmente adotadas pelos Estados para a definição de suas ações de mudanças educacionais: a) Baseadas na competitividade; b) Baseadas nos imperativos financeiros e c) Baseadas na equidade.

As reformas Baseadas na Competitividade, de acordo com Carnoy (2002), procuram, antes de tudo, aumentar a produtividade econômica, aprimorando a qualidade da mão de obra. A produtividade é o fator fundamental desse conceito de reforma e todas as ações políticas são voltadas ao aumento do rendimento escolar com notória expansão dos níveis de ensino mesmo que isso implique, em alguns casos, em aumento de recursos e gastos. Estas reformas são classificadas em quatro categorias.

A primeira é a descentralização, nesse princípio é compreendido que a competitividade só pode ser obtida quando o nível de tomada de decisão acontece localmente, isto é, garante-se um maior poder de autonomia para a gestão das ações educativas. A justificativa pauta-se no "princípio de que uma flexibilidade e um controle acentuados permitem uma harmonização mais adequada dos métodos pedagógicos com a clientela atendida e uma responsabilização quanto aos resultados escolares" (CARNOY, 2002, p. 56-57). A esfera de decisão sobre os rumos escolares passa para o nível local onde, em tese, os anseios e necessidades das comunidades locais podem orientar reformas com vistas a assegurar a melhoria do sistema educacional.

A segunda é baseada nos padrões educativos e ocorre inversamente ao conceito de descentralização. Reformas baseadas em padrões educativos tendem a direcionar as ações com vistas ao estabelecimento de padrões normativos a serem alcançados igualitariamente pelas unidades escolares, forçando indiretamente o sistema a centralizar as tomadas de decisões. As orientações e as políticas públicas educacionais nesse caso são direcionadas por fatores externos comparativos, como avaliações em larga escala e indicadores de desempenho.

\begin{tabular}{l|c|c|c|c|c|c|}
\hline () Rev. Educ. Perspec. & Viçosa, $M G$ & v.9 & n.1 & p.104-126 & jan./abr. 2018 & eISSN 2178-8359 \\
\hline
\end{tabular}


Uma terceira categoria é definida como de gestão racionalizada e está baseada no conceito de otimização de ações e maximização de resultados. Isto é, “consiste em desenvolver o esforço e a inovação pedagógicos, ao mesmo tempo em que propõe aos professores determinados métodos de ensino eficazes" (LEVIN, 1993, apud CARNOY, 2002, p. 59). O conceito de gestão racionalizada é amparado pelo argumento de que escolas privadas conseguem obter os mesmos resultados com os mesmos custos financeiros, ou até inferiores, do que escolas do sistema público (WEST, 1997).

Outro argumento é o de que em países em desenvolvimento os recursos deveriam ser focalizados na educação básica, uma vez que, a "taxa social de rentabilidade" é superior aos resultados de investimento no ensino médio e superior. Portanto, pressupõe-se que a "produtividade econômica e o bem social progridem mais em função dos gastos públicos destinados à educação básica e não aos graus superiores” (CARNOY, 2002, p. 59).

O aprimoramento da seleção e formação de professores constitui-se como a quarta categoria, e está associada a uma reforma que visa recrutar professores qualificados para atuação em todos os níveis da educação. De acordo com a OCDE (1992 apud CARNOY, 2002), os elementos complexos da atratividade da profissão compreendem não só os salários relativos dos professores, mas também, o julgamento manifestado pela sociedade a seu respeito, o isolamento parcial que experimentam em seu trabalho e o grau de profissionalismo que lhes é reconhecido pela burocracia da educação. Nesse sentido, a reforma estaria focalizada em proporcionar melhores atrativos para a carreira.

Outro padrão estabelecido no conjunto de reformas na educação são as reformas Baseadas nos Imperativos Financeiros, que se resume, em essência, na redução de gastos com a educação. Com forte amparo de agências e bancos multilaterais como o Fundo Monetário Internacional (FMI), Banco Mundial, e Banco Internacional para Reconstrução e Desenvolvimento (BIRD), as reformas baseadas em imperativos financeiros traçam estratégias de aumento de produtividade com a melhoria de eficácia coletiva, no entanto, com restrição de uso de recursos públicos. Tais reformas possuem uma forte tendência em apoiar a educação básica em níveis elementares em detrimento a níveis superiores.

Outra premissa trata-se da privatização do ensino secundário e superior. No tocante de transferência orçamentária de níveis superiores para inferiores à prerrogativa de financiamento para a educação secundária e superior ficaria, portanto, destinada à iniciativa privada. Essa justificativa é amparada pelo discurso de grande parte dos países em que o acompanhamento dos índices por demandas crescentes por acesso à educação pode levar a um colapso de financiamento. 
A redução de custo por aluno é outra posição defendida pelas reformas baseadas em imperativos financeiros, cujo argumento é o aumento do número de alunos por turma. Considerando o meio socioeconômico dos escolares, os economistas do Banco Mundial concluem que, na faixa de 20 a 45 alunos por professor, a relação aluno/professor não tem nenhum efeito sobre os resultados escolares (CARNOY, 2002).

O último corpo de reformas Baseadas na Equidade trata de ações voltadas às categorias mais desfavorecidas da população, visando ampliar a taxa de sucesso escolar em níveis elementares com o oferecimento de atividades paralelas extraescolares por meio de projetos especiais. Porém, do ponto de vista objetivo, as reformas baseadas na equidade acabam que por adotar medidas restritivas (como as baseadas em imperativos financeiros) direcionando o financiamento para determinadas áreas em detrimento de outras, bem como determina em suas políticas que a taxa de retorno social da educação é maior quando o investimento na educação básica é mais elevado de que em outros níveis superiores.

Para Carnoy (2002) o rendimento escolar é um fator primordial para desempenhar um importante papel no nivelamento do campo de ação. Exemplos de ação reformista dessa natureza estão em investimentos diretos em escolas com baixo rendimento escolar, aplicação de incentivos financeiros por desempenho, e testes nacionais para identificação de déficits educacionais. O quadro 01 ilustra de forma sintetizada as possibilidades de reformas apresentadas.

Quadro 1. Tipos de reformas educativas

\begin{tabular}{|c|c|c|}
\hline Baseadas na Competitividade & $\begin{array}{c}\text { Baseadas nos Imperativos } \\
\text { Financeiros } \\
\end{array}$ & Baseadas na Equidade \\
\hline \multicolumn{3}{|c|}{ Foco de Ação } \\
\hline $\begin{array}{l}\text { Aumento da produtividade } \\
\text { econômica e da qualidade da } \\
\text { mão de obra. }\end{array}$ & $\begin{array}{l}\text { Ajuste estrutural e correção de } \\
\text { desequilíbrio financeiro. }\end{array}$ & $\begin{array}{l}\text { Aumento da igualdade das } \\
\text { possibilidades econômicas. }\end{array}$ \\
\hline \multicolumn{3}{|c|}{ Principais Medidas } \\
\hline $\begin{array}{l}\text { 1. Descentralização } \\
\text { 2. Padrões Educativos } \\
\text { 3. Gestão racionalizada } \\
\text { 4. Seleção de professores }\end{array}$ & $\begin{array}{l}\text { 1. Transferência de } \\
\text { financiamento } \\
\text { 2. Privatização } \\
\text { 3. Redução de custos por aluno }\end{array}$ & $\begin{array}{lrr}\text { 1. Atenção a grupos } \\
\text { desfavorecidos } & \\
\text { 2. Transferência } & \text { de } \\
\text { financiamento } & \end{array}$ \\
\hline
\end{tabular}

Fonte: Carnoy, 2002

Dessa forma, ações pautadas em ampliação da jornada escolar de forma indutora definitiva em um sistema educativo tenderiam a vincular-se a medidas com caráter de aumento de padrões educativos e atenção a grupos desfavorecidos, apoiando-se em premissas baseadas em competitividade e equidade.

Esse pressuposto pode ser compreendido a partir da observação de Libâneo (2016) que assevera que atualmente, as políticas educacionais têm seu lastro em orientações de

\begin{tabular}{l|c|c|c|c|c|c|}
\hline () Rev. Educ. Perspec. & Viçosa, MG & v.9 & n.1 & p.104-126 & jan./abr. 2018 & eISSN 2178-8359 \\
\hline
\end{tabular}


organismos internacionais, desde a adesão do governo brasileiro às recomendações formais expedidas pelas Conferências Mundiais sobre Educação para Todos e outros eventos patrocinados pela Unesco e Banco Mundial.

O contexto de elaboração de estratégias de inserção da educação de tempo integral recai, em grande parte, sobre o discurso da qualidade. O direito à educação de qualidade é um elemento fundamental para a ampliação e a garantia dos demais direitos humanos e sociais, e condição para a própria democracia, e a escola pública universal materializa esse direito (BRASIL, 2009). Assegurar um contexto de qualidade educacional requer condições necessárias para aplicação de medidas que visem equalizar as disparidades e oferecer condições necessárias para que as mudanças ocorram. Para Libâneo (2016), tais condições começaram a ser difundidas pelos organismos internacionais a partir da consolidação do pensamento político econômico pautado em uma doutrina liberal, cujo princípio de ajuste estrutural se assenta no tripé desregulação, privatização e liberalização dos mercados, com foco em políticas de reformas visando à modernização do Estado.

Os modelos de reformas educacionais propostos por Carnoy (2002) seguem tal tendência e padronizam as formas e objetivos da educação a partir do tipo de ajuste necessário para a obtenção de resultados. Seja em termos de reconfiguração do universo escolar, com a implantação de um sistema de educação em tempo integral, seja em termos de ampliação do acesso e permanência na escola.

Silva (2017) indica duas grandes vertentes que remetem ao conceito de reformas no campo das políticas educativas com foco na educação integral. A primeira tem enfoque no investimento em mudanças estruturais (físicas, administrativas e pedagógicas) nas unidades escolares, de modo que elas possam oferecer condições compatíveis com a presença de alunos e professores em tempo integral, chamada de escolas em tempo integral. A segunda vertente procura articular distintas instituições e projetos da sociedade civil organizada oferecendo atividades apenas para parte dos alunos no turno alternativo às aulas e não necessariamente no espaço escolar, com denominação de "alunos em tempo integral".

A segunda vertente se aproxima com os pressupostos da política de ACCs do Estado do Paraná e tem sua origem a partir da fundamentação teórica dos conceitos de educação permanente. "Originalmente eles foram publicados no relatório "Aprender a ser"”, produzido pela UNESCO nos anos 1970, em que havia a "recomendação de articulação entre "atividades extraescolares" e "ensino metódico"” (FAURE, 1972, apud SILVA, 2017, p. 4, grifo do autor). 


\section{AS ACCS COMO AMPLIAÇÃO DA JORNADA ESCOLAR}

A ampliação da jornada escolar não é tema recente e figura constantemente no cenário educacional brasileiro como debate a partir de ações políticas e de gestão. Segundo Souza e Charlot (2016) o debate sobre as temáticas concernentes ao tema passam por uma ampliação do repertório linguístico dificultando a compreensão de fatores históricos e aspectos teóricos. Termos como "educação integral", "jornada ampliada", "escola em tempo integral", "tempo integral", confundem-se constantemente nos discursos no campo da educação.

De acordo com os autores os argumentos centrais tendem a se polarizar a partir de duas perspectivas: aqueles nos quais o discurso pauta-se em uma educação efetivamente integral, e aqueles cujos discursos estão focados no aumento do tempo de aprendizagem.

Mesmo que se considere as diferenças de significados, concepções, tendências, decisões políticas, diferenças sociais e culturais, a expressão Educação Integral, como tem sido discutida hoje no Brasil e em diferentes países, de modo geral, se relaciona a um tempo a mais na escola (SOUZA; CHARLOT, 2016, p. 1074).

Já para Gabriel e Cavalieri (2012, p. 279) "a educação integral caracteriza-se como uma educação com responsabilidades ampliadas, em geral com forte atuação nas áreas da cultura, dos esportes, das artes, ultrapassando a atuação restrita à típica instrução escolar”. Em contraposição, Gadotti (2009) aponta que não compete à escola suprir todas as deficiências da ausência de determinadas políticas sociais. Para o autor, a escola precisa cumprir bem a sua função de ensinar.

Menezes (2012) aponta que embora o conceito de Educação Integral esteja em constante movimento, o mesmo é considerado ação estratégica voltada para a garantia da atenção e do desenvolvimento integral de crianças e jovens. Tal posicionamento corrobora com o disposto na Instrução 07/2012 da Secretaria de Estado da Educação do Paraná (SEED/PR) sobre a política de ACCs. O princípio do desenvolvimento integral é observado quando da constituição dos macrocampos propostos para o desenvolvimento dos projetos: Aprofundamento da aprendizagem, Experimentação e Iniciação Científica, Cultura e Arte, Esporte e Lazer, Tecnologias da Informação, da Comunicação e uso de mídias, Meio Ambiente, Direitos Humanos, Promoção da Saúde, e Mundo do Trabalho e Geração de Renda.

A adoção gradativa de políticas que visem ampliar a oferta de escolas de tempo integral vem se consolidando como prática recorrente de um processo orientado pelos pressupostos do direito universal à educação. De acordo com Cavaliere (2014) a Lei de Diretrizes e Bases da Educação Nacional (LDBEN) afirma em seus Artigos 34 e 87 que a ampliação da jornada escolar será feita "progressivamente", "a critério dos sistemas de ensino".

\begin{tabular}{l|c|c|c|c|c|c|} 
(C) Rev. Educ. Perspec. & Viçosa, $M G$ & v.9 & n.1 & p.104-126 & jan./abr. 2018 & eISSN 2178-8359 \\
\hline
\end{tabular}


O modelo proposto no Estado do Paraná não é único, e segue parâmetros já dispostos em outros documentos oficiais. Segundo Cavaliere (2014) alguns itens que introduzem as metas do Plano Nacional de Educação (PNE) são particularmente importantes para as propostas de escolas de tempo integral. A autora relata que no Art. $2^{\circ}$, item IV, surge pela primeira vez a palavra "contraturno", e no item VII aparece também pela primeira vez a formulação "educandos sob responsabilidade da escola para além da jornada escolar", tais definições conceituais foram essenciais para a elaboração de políticas públicas de ampliação de jornada escolar especialmente o Programa Mais Educação do Governo Federal, e no caso em questão, o Programa de ACCs da SEED/PR.

Os argumentos neste caso caminham em direção a complementariedade do processo educacional em contraturno escolar. Tal propositura ampara-se no contexto da expectativa social sustentada pelo discurso de assistência e salvaguarda dos alunos em período estendido (o que beneficiaria famílias em que os pais trabalham em período integral), da melhoria da educação (por meio da oferta de atividades de reforço escolar), e da socialização como fator de emancipação (por meio da oferta de projetos nas mais diversas áreas do conhecimento). Os questionamentos a partir de tais concepções se iniciam a partir da ausência de diálogo das ações educativas escolares formais (educação básica) com as atividades propostas em contraturno. Segundo Silva (2013), uma ampliação da jornada pouco ou nada amarrada ao projeto pedagógico da escola ou ancorada na ideia da complementação, ou da mera ocupação do tempo, é insuficiente frente ao desafio educacional que o Brasil possui.

No mesmo sentido, Cavaliere (2014) afirma que a solução organizacional do tempo integral dessa forma não constrói uma escola efetivamente de tempo integral e nem cria as condições para o desenvolvimento da chamada "educação integral", apenas oferece um regime escolar diferenciado para os alunos "mais necessitados", gerando também uma excessiva dispersão de objetivos.

Do ponto de vista gerencial e organizacional, a proposta da SEED/PR tenta minimizar tais características ao tentar estabelecer efetivo vinculo entre as ACCs propostas e a rotina da escola. De acordo com a Instrução 07/2012 SEED/PR, o processo de aprovação da inclusão da escola no sistema de ACCs requer: 1) a submissão de proposta de, ao menos 5 atividades vinculadas aos macrocampos propostos, para um mesmo grupo de alunos (ensino fundamental, médio ou educação especial) durante 5 dias da semana; 2) verificação da comprovação da inserção de tais atividades no projeto político pedagógico da escola; 3) encaminhamento da documentação do Núcleo Regional de Educação (NRE) ao Departamento de Educação Básica/Coordenação da Educação Integral para análise e parecer; e 4) com autorização concedida, inclusão da escola no Sistema de Acompanhamento de Atividades Curriculares Complementares (CELEPAR/SEED).

\begin{tabular}{l|c|c|c|c|c|c|} 
(C) Rev. Educ. Perspec. & Viçosa, $M G$ & v.9 & n.1 & p.104-126 & jan./abr. 2018 & eISSN 2178-8359 \\
\hline
\end{tabular}


A vinculação das ACCs a outros projetos já existentes nas escolas é desencorajado pela SEED/PR, no intuito de assegurar a execução de uma proposta própria. Escolas que já ofertem atividades vinculadas ao Programa Mais Educação, Programa Segundo Tempo, Escola Técnica Aberta do Brasil, Esporte Cidadão Unilever-Precuni, e Ensino Médio Inovador, não serão priorizadas conforme disposto na Instrução 07/2012.

A organização didática das ações segue orientação expressa de macrocampos prioritários de atenção aos quais os projetos devem ser vinculados nas escolas. Obrigatoriamente a escola deve ofertar projetos cujo foco centra-se no aprofundamento da aprendizagem, uma clara observância aos princípios de complementariedade escolar com reforço de ação junto à educação básica. Além disso, a sequência prioriza ações nos campos da experimentação e iniciação científica, direitos humanos, meio ambiente e promoção da saúde, tais áreas são vistas como importantes na consolidação do processo de conhecimento vinculado ao aprendizado formal da escola. E como área eletiva, os macrocampos de cultura e arte, mundo do trabalho e geração de renda, tecnologia da informação e, esporte e lazer, figuram como áreas em que ficam a critério da comunidade escolar a opção pelo desenvolvimento de projetos uma vez observada a demanda e os seus objetivos.

Quadro 2. Macrocampos e orientações diretivas da SEED/PR

\begin{tabular}{|c|}
\hline Macrocampo Obrigatório \\
Aprofundamento da Aprendizagem \\
Macrocampos Prioritários \\
Experimentação e Iniciação Científica \\
Direitos Humanos \\
Meio Ambiente \\
Promoção da Saúde \\
Macrocampos Eletivos \\
Cultura e Arte \\
Mundo do Trabalho e Geração de Rendas \\
Tecnologia da Informação, Comunicação e uso de mídias \\
Esporte e Lazer \\
Fonte: Instrução Normativa $07 / 2012$ SEED/PR
\end{tabular}

A configuração de uma política com vistas à implantação gradual de uma escola de tempo integral, tal qual o modelo de ACCs, indica uma intencionalidade e uma objetividade sem que, contudo, os resultados expressos possam confirmar uma tendência de efetividade em curto prazo, tanto em aspectos qualitativos de rendimento escolar, quanto de quantitativos de acesso e permanência.

De acordo com Coelho (2012) a ampliação da jornada escolar dificilmente consegue influir na qualidade da educação, se não se constitui como uma Educação Integral, entendida esta como formação completa do ser humano. Segundo a autora, outro fator a ser observado é que a ampliação da jornada escolar, com Educação Integral, deve começar no ensino fundamental, mais precisamente nos anos iniciais. No que tange aos pressupostos da política,

\begin{tabular}{l|l|l|l|l|l|l} 
(C) Rev. Educ. Perspec. & Viçosa, $M G$ & v.9 & n.1 & p.104-126 & jan./abr. 2018 & eISSN 2178-8359 \\
\hline
\end{tabular}


não há, por parte das normativas legais, especificidades quanto a escolha do nível educacional ofertado pela escola que deseja ingressar no programa de ACCs.

\section{METODOLOGIA E DISCUSSÃO DOS DADOS}

Essa pesquisa foi caracterizada como de abordagem quantitativa de levantamento e objetivou traçar um panorama das atividades curriculares complementares em escolas estaduais do Paraná. Para tanto, a compreensão deste panorama teve como foco cidades do interior com população igual ou superior a 100.000 habitantes, abrangendo um total de 19 cidades paranaenses e 372 escolas.

A coleta de dados foi realizada junto à base de dados do MEC, o Data Escola Brasil e as informações foram lançadas em uma base de dados elaborada com as principais variáveis de interesse: localização, tipo de ensino ofertado, matrícula, projetos ofertados, matrículas em projetos, nota do Índice de Desenvolvimento da Educação Básica (Ideb). Apesar do conceito de qualidade educacional ser polissêmico, a utilização do Ideb como fator de qualidade é relevante neste estudo, uma vez que, é o principal indicador quantitativo usado no Brasil para calcular os valores de escores de rendimento para as escolas servindo de base para a formulação de políticas educacionais em diversos níveis.

Os dados foram posteriormente tratados no software SPSS 20.0 utilizando-se da estatística descritiva e da abordagem não-paramétrica de análise. Para a comparação e estabelecimento de possíveis associações ou diferenças entre as cidades e escolas foi utilizado o teste de Quiquadrado e correlação de Spearman, e para determinar a significância dos dados adotou-se o valor de $\mathrm{p} \leq 0,05$ como referência.

As informações obtidas mostram a forma como se configuram, em seu aspecto amplo, os projetos de contraturno escolar instituídos pela Resolução 1690/2011 (PARANÁ, 2011). Foi possível observar que o processo de implantação de atividades de contraturno nas escolas já se configura como uma realidade na maioria das escolas como mostra a Tabela 1.

Tabela 1. Municípios e quantidade de escolas da pesquisa

\begin{tabular}{lcccc}
\hline \multicolumn{1}{c}{ Municípios } & População & $\begin{array}{c}\text { Escolas } \\
\text { Estaduais }\end{array}$ & $\begin{array}{c}\text { Escolas } \\
\text { Estaduais com } \\
\text { Atividades } \\
\text { Complementares }\end{array}$ & $\begin{array}{c}\text { \% de escolas com } \\
\text { ACCs }\end{array}$ \\
\hline Londrina & 548.000 & 65 & 56 & 86,15 \\
Maringá & 397.000 & 31 & 29 & 93,54 \\
Ponta Grossa & 337.000 & 43 & 36 & 83,72 \\
Cascavel & 312.000 & 37 & 36 & 97,29
\end{tabular}

\begin{tabular}{l|l} 
n.1 & p.104-126 \\
\hline
\end{tabular}

\begin{tabular}{|l|l|} 
jan./abr. 2018 & eISSN 2178-8359 \\
\hline
\end{tabular}




\begin{tabular}{lcccc} 
S.J. Pinhais & 297.000 & 28 & 23 & 82,14 \\
Foz do Iguaçu & 263.000 & 28 & 23 & 82,14 \\
Colombo & 232.000 & 22 & 13 & 59,09 \\
Guarapuava & 178.000 & 25 & 22 & 88,00 \\
Paranaguá & 150.000 & 19 & 16 & 84,21 \\
Araucária & 133.000 & 16 & 9 & 56,25 \\
Toledo & 132.000 & 27 & 25 & 92,59 \\
Apucarana & 130.000 & 16 & 15 & 93,75 \\
Pinhais & 127.000 & 13 & 9 & 69,23 \\
Campo Largo & 124.000 & 17 & 8 & 47,05 \\
Arapongas & 115.000 & 14 & 13 & 92,85 \\
Alm. Tamandaré & 112.000 & 16 & 11 & 68,75 \\
Umuarama & 108.000 & 18 & 15 & 83,33 \\
Piraquara & 104.000 & 10 & 2 & 20,00 \\
Cambé & 103.000 & 13 & 11 & 84,61 \\
\hline Total & & 372 & 81,22 \\
\hline Fonte: Censo IBGE (2010); DataEscolaBrasil (2016). & &
\end{tabular}

O percentual de adesão às atividades curriculares complementares é de 81,22\% das escolas pesquisadas, indicando que essa política pública está em processo de consolidação. Do total de escolas analisadas, 359 ou 96,5\% estão localizadas na zona urbana, enquanto que apenas 13 escolas ou 3,4\% do total estão localizadas em zonas rurais dos municípios. Em relação à modalidade de ensino ofertada há uma divisão muito semelhante entre ensino fundamental e ensino médio, como pode ser observado na tabela 2.

Tabela 2. Modalidade de Ensino Ofertado

\begin{tabular}{lccc}
\hline \multicolumn{1}{c}{$\begin{array}{c}\text { Escolas } \\
\text { Modalidade de Ensino }\end{array}$} & $\%$ & Média Matrícula \\
\hline & 1 & 0,3 & 102 \\
Educação Infantil & 359 & 96,5 & 428 \\
Ensino Fundamental & 328 & 88,2 & 312 \\
Ensino Médio & Total de 372 escolas \\
\hline \multicolumn{4}{l}{} \\
\hline Fonte: Pesquisa autores
\end{tabular}

O perfil geral de projetos desenvolvidos nas escolas analisadas é variado, porém, segue uma tendência de centralização em alguns projetos que possuem uma frequência mais acentuada nas escolas, como podem ser observados na tabela 3, que mostra as 20 maiores frequências encontradas.

Tabela 3. Frequência geral de projetos de ACCs e matrículas

\begin{tabular}{|c|c|c|c|c|c|c|c|}
\hline \multicolumn{3}{|l|}{ Projetos Implantados } & & Projetos & $\%$ & Média Matr. & Total Matr. \\
\hline \multicolumn{3}{|l|}{ Línguas Estrangeiras } & & 261 & 18,4 & 42,5 & 11.072 \\
\hline \multicolumn{3}{|l|}{ Futsal } & & 138 & 9,8 & 33,8 & 4.705 \\
\hline \multicolumn{3}{|l|}{ Voleibol } & & 69 & 4,9 & 35,1 & 2.393 \\
\hline \multicolumn{4}{|l|}{ Leitura de Produção de texto } & 53 & 3,7 & 45,5 & 2.368 \\
\hline (C) Rev. Educ. Perspec. & Viçosa, $M G$ & v.9 & n.1 & p.10 & -126 & jan./abr. 2018 & eISSN 2178-8359 \\
\hline
\end{tabular}


Atletismo e múltiplas vivências esportivas

$50 \quad 3,5$

56,1

Danças

Tênis de mesa

Orientação de estudos e leitura

Atletismo

Xadrez

Conservação de solo e composteira

Teatro

Outra categoria de acompanhamento pedagógico

Matemática

Basquete

Outra categoria de esporte e lazer

Handebol

Letramento e alfabetização

Outra categoria de artes, cultura e educação patrimonial

Fonte: pesquisa autores
32,6

46,2

$45 \quad 3,2$

$41 \quad 2,9$

$36 \quad 2,5$

$35 \quad 2,5$

43,6

58,3

44,7

27,3

44,9

41,0

51,9

32,3

24,9

43,5

29,7

56,6

50,3
2.865

1.438

1.895

1.570

2.101

1.433

904

1.393

1.273

1.350

809

598

1.044

684

1.303

1.108

Quando observado a estratificação da implantação de tais projetos por cidade (tabela 4), percebe-se que a tendência de padronização se repete, indicando que apenas dois projetos (Línguas Estrangeiras e Futsal) concentram 28,2\% do total de projetos desenvolvidos. No entanto, há um predomínio de implantação do projeto de Línguas Estrangeiras nas escolas, sendo que em 17 cidades, tais projetos figuram como os mais desenvolvidos, seguidos de projetos da área de esportes.

Tabela 4. Projetos com maior frequência de implantação por cidade

\begin{tabular}{|c|c|c|c|c|c|c|c|}
\hline Cidade & Projeto & $\%$ & Projeto & $\%$ & Projeto & $\%$ & $\mathrm{~N}$ \\
\hline Londrina & $\begin{array}{l}\text { Línguas } \\
\text { Estrangeiras }\end{array}$ & 21,7 & Futsal & 7,7 & $\begin{array}{l}\text { Leitura e Prod. } \\
\text { Texto }\end{array}$ & 6,3 & 207 \\
\hline Maringá & $\begin{array}{l}\text { Línguas } \\
\text { Estrangeiras }\end{array}$ & 20,5 & Futsal & 12,0 & Voleibol & 6,0 & 107 \\
\hline Ponta Grossa & $\begin{array}{l}\text { Línguas } \\
\text { Estrangeiras }\end{array}$ & 15,4 & Futsal & 11,2 & Tênis de Mesa & 5,6 & 143 \\
\hline Cascavel & $\begin{array}{l}\text { Línguas } \\
\text { Estrangeiras }\end{array}$ & 18,4 & Futsal & 11,2 & $\begin{array}{l}\text { Leitura e P. } \\
\text { Texto }\end{array}$ & 5,9 & 152 \\
\hline $\begin{array}{l}\text { São José dos } \\
\text { Pinhais }\end{array}$ & $\begin{array}{l}\text { Línguas } \\
\text { Estrangeiras }\end{array}$ & 23,8 & Atletismo & 6,3 & Voleibol & 4,3 & 63 \\
\hline Foz do Iguaçu & $\begin{array}{l}\text { Línguas } \\
\text { Estrangeiras }\end{array}$ & 15,8 & $\begin{array}{l}\text { Atletismo e m. } \\
\text { vivências }\end{array}$ & 10,5 & $\begin{array}{l}\text { Orientação de } \\
\text { Estud. }\end{array}$ & 9,5 & 95 \\
\hline Colombo & Futsal & 16,7 & $\begin{array}{l}\text { Línguas } \\
\text { Estrangeiras }\end{array}$ & 12,5 & Voleibol & 8,3 & 24 \\
\hline Guarapuava & $\begin{array}{l}\text { Línguas } \\
\text { Estrangeiras }\end{array}$ & 19,1 & Futsal & 8,5 & $\begin{array}{l}\text { Atletismo e m. } \\
\text { vivência }\end{array}$ & 7,4 & 94 \\
\hline Paranaguá & $\begin{array}{l}\text { Línguas } \\
\text { Estrangeiras }\end{array}$ & 16,9 & $\begin{array}{l}\text { Leitura e Prod. } \\
\text { Texto }\end{array}$ & 7,0 & $\begin{array}{l}\text { Economia } \\
\text { solidária }\end{array}$ & 7,0 & 71 \\
\hline Araucária & $\begin{array}{l}\text { Línguas } \\
\text { Estrangeiras }\end{array}$ & 57,1 & Futsal & 7,1 & $\begin{array}{l}\text { Leitura e Prod. } \\
\text { Texto }\end{array}$ & 7,1 & 14 \\
\hline Toledo & $\begin{array}{l}\text { Línguas } \\
\text { Estrangeiras }\end{array}$ & 14,5 & Futsal & 10,9 & Danças & 8,2 & 110 \\
\hline (C) Rev. Edu & erspec. & Viçosa, $M G$ & n.1 & p.104-126 & jan./abr. 2018 & & $2178-8359$ \\
\hline
\end{tabular}




\begin{tabular}{|c|c|c|c|c|c|c|}
\hline Apucarana & $\begin{array}{l}\text { Línguas } \\
\text { Estrangeiras }\end{array}$ & 18,3 & Futsal & 15,5 & $\begin{array}{l}\text { Economia } \\
\text { solidária }\end{array}$ & 5,6 \\
\hline Pinhais & $\begin{array}{l}\text { Línguas } \\
\text { Estrangeiras }\end{array}$ & 12,9 & Futsal & 9,7 & $\begin{array}{l}\text { Orientação de } \\
\text { Estud. }\end{array}$ & 6,5 \\
\hline Campo Largo & Futsal & 22,2 & $\begin{array}{l}\text { Línguas } \\
\text { Estrangeiras }\end{array}$ & 14,8 & Voleibol & 11,1 \\
\hline Arapongas & $\begin{array}{l}\text { Línguas } \\
\text { Estrangeiras }\end{array}$ & 15,8 & Futsal & 10,5 & Voleibol & 10,5 \\
\hline Almirante & Línguas & 10,0 & Teatro & 7,5 & Voleibol & 5,0 \\
\hline Tamandaré & Estrangeiras & & & & & \\
\hline Umuarama & $\begin{array}{l}\text { Línguas } \\
\text { Estrangeiras }\end{array}$ & 18,5 & Futsal & 14,8 & $\begin{array}{l}\text { Conservação do } \\
\text { solo }\end{array}$ & 5,3 \\
\hline Piraquara & Futsal & 28,6 & Voleibol & 28,6 & $\begin{array}{l}\text { Línguas } \\
\text { Estrangeiras }\end{array}$ & 14,3 \\
\hline Cambé & $\begin{array}{l}\text { Línguas } \\
\text { Estrangeiras }\end{array}$ & 25,0 & Voleibol & 11,1 & Futsal & 5,6 \\
\hline
\end{tabular}

Total de Escolas Analisadas: 372

Total de Projetos Encontrados em todas as áreas: 1.413 Média 3,7 projetos implantados por escola

Fonte: pesquisa autores

Em relação a participação dos alunos nos projetos, foi realizado um levantamento sistemático de matrícula por projetos os quais foram cruzados com a taxa de matrícula da escola (educação básica), gerando uma taxa proporcional. Para isso foi utilizada a seguinte equação:

NMAC x 100

\section{NTAE}

Onde: $\mathrm{NMAC}=\mathrm{N}^{\mathrm{o}}$ de alunos matriculados nas atividades complementares $\mathrm{NTAE}=\mathrm{N}^{\circ}$ de alunos total matriculados na escola

Dessa forma, foi gerada uma taxa de proporcionalidade de matrícula ${ }^{\mathrm{i}}$ nos projetos de atividade complementar em relação ao total de matrículas da educação básica na escola. A média percentual de participação nas ACCs em relação a média de matrículas nas escolas pode ser observada na tabela 5 .

Tabela 5. Perfil do Ideb e Participação nas ACCs nas escolas

\begin{tabular}{|c|c|c|c|c|c|c|c|}
\hline & \multicolumn{3}{|c|}{$\begin{array}{c}\text { Média Ideb das Escolas po } \\
\text { cidade }\end{array}$} & \multicolumn{3}{|c|}{$\begin{array}{c}\text { Taxa Proporcional } \\
\text { Média ACCs por cidade }\end{array}$} & \\
\hline Londrina & \multicolumn{3}{|c|}{3,81} & \multicolumn{4}{|c|}{$26,19 \%$} \\
\hline Maringá & \multicolumn{3}{|c|}{4,07} & \multicolumn{4}{|c|}{$30,56 \%$} \\
\hline Ponta Grossa & \multicolumn{3}{|c|}{3,96} & \multicolumn{4}{|c|}{$36,91 \%$} \\
\hline (C) Rev. Educ. Perspec. & Viçosa, $M G$ & v.9 & n.1 & p.104-126 & jan./abr. 2018 & eISS & $2178-8359$ \\
\hline
\end{tabular}




\begin{tabular}{lcc} 
Cascavel & 4,43 & $48,68 \%$ \\
São José dos Pinhais & 4,00 & $20,05 \%$ \\
Foz do Iguaçu & 4,11 & $20,12 \%$ \\
Colombo & 3,17 & $6,09 \%$ \\
Guarapuava & 3,89 & $30,86 \%$ \\
Paranaguá & 3,04 & $42,51 \%$ \\
Araucária & 3,50 & $10,66 \%$ \\
Toledo & 4,64 & $59,92 \%$ \\
Apucarana & 4,24 & $52,90 \%$ \\
Pinhais & 3,85 & $21,65 \%$ \\
Campo Largo & 4,67 & $17,38 \%$ \\
Arapongas & 4,37 & $33,90 \%$ \\
Almirante Tamandaré & 3,45 & $48,62 \%$ \\
Umuarama & 4,36 & $58,10 \%$ \\
Piraquara & 3,55 & $5,76 \%$ \\
Cambé & 3,98 & $45,22 \%$ \\
\hline GERAL & 3,95 & $32,42 \%$ \\
\hline
\end{tabular}

Fonte: pesquisa autores

Como forma de tentar compreender o macro panorama posto a partir da estratificação em grupos de escolas, foram criadas três categorias de frequência a partir da divisão estatística por quartis. O posicionamento das escolas obedeceu a seguinte classificação: 1) baixa adesão: escolas com menos de $7,90 \%$ de participação nos projetos em relação ao total de alunos, 2) média adesão: escolas com percentuais entre $7,91 \%$ e $39,15 \%$ de participação nos projetos em relação ao total de alunos, e 3) alta adesão: escolas com percentuais acima de $39,15 \%$ de participação nos projetos em relação ao total de alunos, como mostra o quadro 3.

Quadro 3. Distribuição da Taxa Proporcional por quartil

\begin{tabular}{|c|c|c|}
\hline Quartil 25 (Q1) & Quartil 25-75 (Q2-3) & Quartil 75 (Q4) \\
\hline até 7,90\% & entre 7,91\% e 39,15\% & acima de 39,15\% \\
\hline Baixa Participação & Média Participação & Alta Participação \\
\hline
\end{tabular}

Fonte: pesquisa autores

A disposição por cidade a partir da distribuição pode ser observada na tabela 6 .

Tabela 6. Relação taxa proporcional de matrícula em projeto e matrícula escolar

\begin{tabular}{|c|c|c|c|c|c|c|c|c|}
\hline \multirow{3}{*}{ Cidade } & \multicolumn{6}{|c|}{ Relação Taxa Proporcional } & \multirow{2}{*}{\multicolumn{2}{|c|}{$\begin{array}{c}\text { TOTAL } \\
\text { ESCOLAS }\end{array}$}} \\
\hline & \multicolumn{2}{|c|}{$\begin{array}{c}\text { Baixa } \\
\text { (Q1) }\end{array}$} & \multicolumn{2}{|c|}{$\begin{array}{l}\text { Média } \\
(\mathrm{Q} 2-3)\end{array}$} & \multicolumn{2}{|c|}{$\begin{array}{l}\text { Alta } \\
\text { (Q4) }\end{array}$} & & \\
\hline & $\mathrm{F}$ & $\%$ & $\mathrm{~F}$ & $\%$ & $\mathrm{~F}$ & $\%$ & $\mathrm{~F}$ & $\%$ \\
\hline Londrina & 16 & 28,6 & 30 & 53,6 & 10 & 17,9 & 56 & 100 \\
\hline Maringá & 8 & 27,6 & 15 & 51,7 & 6 & 20,7 & 29 & 100 \\
\hline Ponta Grossa & 12 & 33,3 & 11 & 30,6 & 13 & 36,1 & 36 & 100 \\
\hline Cascavel & 3 & 8,3 & 20 & 55,6 & 13 & 36,1 & 36 & 100 \\
\hline São J. dos Pinhais & 13 & 56,5 & 7 & 30,4 & 3 & 13,0 & 23 & 100 \\
\hline Foz do Iguaçu & 5 & 21,7 & 16 & 69,6 & 2 & 8,7 & 23 & 100 \\
\hline Colombo & 8 & 61,5 & 5 & 38,5 & 0 & 0,0 & 13 & 100 \\
\hline (C) Rev. Educ. Perspec. & & $a, M G$ & v.9 & n.1 & p.104-126 & jan./abr & & eISSN 2178-8359 \\
\hline
\end{tabular}




\section{Bancentio}

doi: 10.22294/eduper/ppge/ufv.v9i1.909

\begin{tabular}{lcccccccc} 
Guarapuava & 3 & 13,6 & 13 & 59,1 & 6 & 27,3 & 22 & 100 \\
Paranaguá & 3 & 18,8 & 10 & 62,5 & 3 & 18,8 & 16 & 100 \\
Araucária & 5 & 55,6 & 3 & 33,3 & 1 & 11,1 & 9 & 100 \\
Toledo & 2 & 8,0 & 11 & 44,0 & 12 & 48,0 & 25 & 100 \\
Apucarana & 0 & 0,0 & 9 & 60,0 & 6 & 40,0 & 15 & 100 \\
Pinhais & 3 & 33,3 & 4 & 44,4 & 2 & 22,2 & 9 & 100 \\
Campo Largo & 2 & 25,0 & 5 & 62,5 & 1 & 12,5 & 8 & 100 \\
Arapongas & 2 & 15,4 & 10 & 76,9 & 1 & 7,7 & 13 & 100 \\
Alm. Tamandaré & 3 & 27,3 & 2 & 18,2 & 6 & 54,5 & 11 & 100 \\
Umuarama & 0 & 0,0 & 10 & 66,7 & 5 & 33,3 & 15 & 100 \\
Piraquara & 2 & 100,0 & 0 & 0,0 & 0 & 0,0 & 2 & 100 \\
Cambé & 3 & 27,3 & 6 & 54,5 & 2 & 18,2 & 11 & 100 \\
\hline & & & & & & & & \multicolumn{4}{c}{$\mathrm{X}^{2}=83.865 \mathrm{p}=0,000$} \\
\hline
\end{tabular}

Fonte: pesquisa autores

É possível observar que há diferença significativa $(\mathrm{p}=0,001)$ entre as cidades analisadas quando observado o posicionamento a partir do agrupamento por quartis. Ao pensar em uma política de atividade curricular complementar, como processo inicial de implantação de uma escola de tempo integral, em um processo de reforma educativa infere-se que tal política pública não está bem definida nos objetivos escolares, uma vez que há $81,22 \%$ de adesão das escolas a essa proposta nas cidades analisadas, porém $75 \%$ dessas escolas apresentam taxas proporcionais de participação entre 0,1 e $39,15 \%$ dos alunos regularmente matriculados.

Um dos princípios apontados na Resolução 1690/2011 da Secretaria de Educação do Estado do Paraná coloca o programa de ACCs como fator de melhoria da qualidade do ensino. Como o conceito de "qualidade" é polissêmico e subjetivo, optou-se por utilizar a padronização de um indicador de avaliação externa que pudesse ser testado, nesse caso o Ideb das escolas.

O Ideb de uma escola ou de uma rede de ensino é definido como o produto de um indicador de desempenho, tomado como o nível médio da proficiência dos alunos da escola ou sistema, obtido na Prova Brasil, por um indicador de rendimento, definido como o valor médio das taxas de aprovação da escola ou sistema, obtido no Censo Escolar (SOARES; XAVIER, 2013, p. 906, grifos dos autores).

Segundo os autores, "um dos motivos da grande respeitabilidade que o Ideb obteve é o fato de agregar, em um único indicador, uma medida de desempenho e outra de rendimento, dimensões fundamentais para uma análise relevante de sistemas de educação básica" (SOARES; XAVIER, 2013, p. 906).

Comparada a taxa proporcional de matrícula em projetos das escolas com o indicador de desempenho da escola na educação básica, não é possível encontrar associações positivas entre as variáveis como mostra a tabela 7. 
Tabela 7. Ideb e Taxa média matrícula ACC por quartis

\begin{tabular}{|c|c|c|c|c|c|c|}
\hline \multirow{3}{*}{ Ideb } & \multicolumn{6}{|c|}{ Taxa proporcional ACCs segmentada por quartis } \\
\hline & \multicolumn{2}{|c|}{$\begin{array}{c}\text { Baixa } \\
\text { (Q1) }\end{array}$} & \multicolumn{2}{|c|}{$\begin{array}{l}\text { Média } \\
\text { (Q2-3) }\end{array}$} & \multicolumn{2}{|c|}{$\begin{array}{l}\text { Alta } \\
(\mathrm{Q} 4)\end{array}$} \\
\hline & $\mathrm{F}$ & $\%$ & $\mathrm{~F}$ & $\%$ & $\mathrm{~F}$ & $\%$ \\
\hline$>3,5$ Baixo & 28 & 33,7 & 39 & 21,9 & 19 & 24,1 \\
\hline 3,6 a 4,5 Médio Baixo & 35 & 42,2 & 91 & 51,1 & 43 & 54,4 \\
\hline 4,56 a 5,5 Médio & 17 & 20,5 & 41 & 23,0 & 16 & 20,3 \\
\hline 5,6 a 6,5 Médio Alto & 3 & 3,6 & 7 & 3,9 & 1 & 1,3 \\
\hline \multirow[t]{2}{*}{ Total } & 83 & 100 & 178 & 100 & 79 & 100 \\
\hline & & & & 6.096 & e R & $=0,54$ \\
\hline
\end{tabular}

Fonte: Pesquisa autores

Uma hipótese seria a de que as maiores frequências de projetos implantados nas escolas (Línguas Estrangeiras e Futsal) podem influenciar para a não associação observada, uma vez que o indicador do Ideb focaliza o rendimento em português e matemática e taxa de aprovação escolar. Nesse sentido, outros projetos encontrados em frequência menor, como Leitura e Produção de texto, Orientação de estudos e leitura, e Matemática, poderiam auxiliar no reposicionamento da escola no indicador. A análise mostrou uma correlação positiva entre as variáveis, isso pode indicar que enquanto a taxa de matrícula nas ACCs sobe a nota do Ideb tende a subir também, sendo o inverso também verdadeiro. No entanto, tal correlação não se mostrou estatisticamente significativa $(\mathrm{p}=0,542)$.

Como limitação do modelo, cabe informar que outros aspectos de natureza qualitativa podem influenciar diretamente o resultado encontrado. Recursos humanos, insumos, infraestrutura, participação democrática da comunidade escolar na escolha dos projetos, envolvimento da comunidade nas ações, bem como, a articulação e a relação direta entre o projeto político pedagógico da escola (PPP) e os projetos de ACCs, são fatores decisivos que podem influenciar o indicador para além da taxa proporcional de matrícula. No entanto, como macro análise tal informação se torna relevante para observar o comportamento de uma política educacional embrionária frente a um possível processo de reforma educativa em médio prazo.

\section{CONSIDERAÇÕES FINAIS}

A ampliação da jornada escolar dentro de um viés de readequação de tempo e espaço das escolas estaduais requer, para além de intenções didáticas, um aparato logístico de recursos humanos e insumos que possibilite a sua execução a partir de uma vertente reformadora. No que tange aos pressupostos teóricos apontados por Carnoy (2002), a proposta de ACCs da $\mathrm{SEED} / \mathrm{PR}$ é orientada para os fatores de competitividade e equidade educacional, uma vez 
que o estabelecimento de padrões educativos e garantia de acesso à educação de grupos desfavorecidos estão presentes na proposta.

A política de ACCs fomentada pela SEED/PR caminha no mesmo sentido de outras políticas atualmente em vigor no país cujo objetivo é a ampliação do tempo da jornada escolar. Assegurar novas oportunidades educativas e associá-las a um viés de melhoria da qualidade da educação aparece como pressuposto nos documentos da secretaria que instituem as atividades nas escolas estaduais paranaenses.

Observado o quantitativo de escolas estaduais por cidade e o quantitativo dessas que ingressaram no sistema de ACCs $(81,22 \%)$, é possível afirmar que a gestão escolar das unidades acreditam que a política proposta possa ser de interesse da comunidade escolar, uma vez que, a adesão é voluntária e segue roteiro prévio a ser cumprido para a formalização do ingresso. No que tange aos aspectos pedagógicos, a divisão das ações em macrocampos distintos possibilita uma flexibilização de propostas e conteúdos de ACCs de acordo com a característica e demanda das unidades escolares. A aplicação prática dessas ações, no entanto, mostrou centralização de ação em projetos pontuais nas cidades analisadas.

Com um panorama abrangente, a taxa proporcional de participação nas ACCs em comparação com as matrículas escolares é da ordem de 32\%, índice que pode ser considerado baixo levando-se em consideração os objetivos da política. Da mesma forma, o cruzamento da taxa proporcional com o Ideb não mostrou significância estatística entre as variáveis, indicando que, a partir dos dados levantados a maior ou menor participação em ACCs não influi no indicador da escola.

Para concluir, os argumentos são reforçados em favor de ajustes nos modelos tradicionais de educação com vistas à ampliação de oportunidades educativas, porém com foco em ações de gestão que possibilitem uma correta articulação entre diferentes propostas, cujo intuito seja a oferta de uma educação que não se limite apenas a uma concepção temporal de ampliação de jornada escolar, mas que repense a instituição escolar como um lócus de aprendizagem e convivência.

\section{REFERÊNCIAS}

ALTMANN, Helena. Influências do Banco Mundial no projeto educacional brasileiro. Educação e Pesquisa, São Paulo, v. 28, n. 1, p. 77-89, jan./jun. 2002.

BELLONI, Isaura; MAGALHÃES, Heitor de; SOUSA, Luzia Costa de. Metodologia de Avaliação em Políticas Públicas. São Paulo: Cortez, 2007.

\begin{tabular}{l|c|c|c|c|c|c} 
() Rev. Educ. Perspec. & Viçosa, $M G$ & v.9 & n.1 & p.104-126 & jan./abr. 2018 & eISSN 2178-8359 \\
\hline
\end{tabular}


BENDRATH. Eduard Angelo. Esporte e Educação Não-Formal no contexto do Programa Abrindo Espaços da UNESCO. Motrivivência. Florianópolis, v. 24, n. 38, p. 123-134, jun. 2012.

BENDRATH, Eduard Angelo. O Programa Escola da Família enquanto Política Pública: Políticas Compensatórias e Avaliação de Rendimento. 2010. 203 f. Dissertação (Mestrado em Educação) - Universidade Estadual Paulista, Presidente Prudente, 2010.

BENDRATH, Eduard Angelo; GOMES, Alberto Albuquerque. Estado, Políticas Públicas e Organismos Internacionais: a educação no foco do debate. InterMeio. Campo Grande, MS, v. 16, n. 32, p. 157-171, jul./dez. 2010.

BRASIL. Ministério da Educação. Educação integral. Brasília: MEC, 2009.

CARNOY, Martin. Mundialização e reforma da educação: o que os planejadores devem saber. Brasília: UNESCO, 2002. 136p.

CAMPOS, Rosânia. As indicações dos organismos internacionais para as políticas nacionais de educação infantil: do direito à focalização. Educação e Pesquisa, São Paulo, v. 39, n. 1, p. 195-209, jan./mar. 2013.

CAVALIERE, Ana Maria. Escola Pública de Tempo Integral no Brasil: Filantropia ou Política de Estado? Educação \& Sociedade, Campinas, v. 35, n. 129, p. 1205-1222, out./dez. 2014.

CAVALIERE, Ana Maria. Apresentação da Seção Temática - Tempo de Escola. Educação \& Realidade. Porto Alegre, v. 41, n. 4, p. 975-984, dez. 2016.

COELHO, Ligia Martha Coimbra da Costa. Alunos no Ensino Fundamental, ampliação da jornada escolar e Educação Integral. Educar em Revista, Curitiba, Brasil, n. 45, p. 73-89, jul./set. 2012.

FERREIRA, Helen Betane; REES, Dilys Karen. Educação Integral e Escola de Tempo Integral em Goiânia. Educação \& Realidade, Porto Alegre, v. 40, n. 1, p. 229-251, jan./mar. 2015.

GABRIEL, Carmen Teresa; CAVALIERI, Ana Maria. Educação Integral e currículo integrado: quando dois conceitos se articulam em um programa. In: MOLL, Jaqueline et al. Caminhos da Educação Integral no Brasil: direito a outros tempos e espaços educativos. Porto Alegre: Penso, 2012.

GADOTTI, Moacir. Educação Integral no Brasil: inovações em processo. São Paulo: Editora e Livraria Instituto Paulo Freire, 2009.

\begin{tabular}{|l|l|l|l|l|l|l} 
(C) Rev. Educ. Perspec. & Viçosa, $M G$ & v.9 & n.1 & p.104-126 & jan./abr. 2018 & eISSN 2178-8359 \\
\hline
\end{tabular}


GARCIA, Maria Manuela Alves; ANADON, Simone Barreto. Reforma educacional, intensificação e autointensificação do trabalho docente. Educação \& Sociedade. Campinas, v. 30, n. 106, p. 63-85, jan./abr. 2009.

KRAWCZYK, Nora. A sustentabilidade da reforma educacional em questão: a posição dos organismos internacionais. Revista Brasileira de Educação, n. 19, p. 43-62, jan./abr. 2002.

LIBÂNEO, José Carlos. Políticas educacionais no Brasil: desfiguramento da escola e do conhecimento escolar. Cadernos de Pesquisa, v. 46, n. 159, p. 38-62, jan./mar. 2016.

MENEZES, Janaina Specht da Silva. Educação em tempo integral: direito e Financiamento. Educar em Revista, Curitiba, Brasil, n. 45, p. 137-152, jul./set. 2012.

PARANÁ. Secretaria do Estado da Educação. Superintendência da Educação. Instrução n ${ }^{\circ}$ 007/2012 - SEED/SUED. Dispõe sobre o Programa de Atividades Complementares Curriculares em contraturno, nas instituições de ensino da Rede Estadual. Paraná, 2012.

PARANÁ. Secretaria do Estado da Educação. Superintendência da Educação. Resolução 1.690 de 27 de abril de 2011. Publicado no Diário Oficial nº 8472 de 24 de Maio de 2011.

SILVA, Bruno Adriano Rodrigues. Interesses, dilemas e a implementação do programa Mais Educação no município de Maricá (RJ). 274 p. 2013. Tese (Doutorado em Educação) - Faculdade de Educação - Universidade Federal do Rio de Janeiro, 2013.

SILVA, Bruno Adriano Rodrigues. A predominância da vertente "alunos em tempo integral" nas discussões sobre o tema da educação integral em tempo integral. Revista Brasileira de Educação. Rio de Janeiro, v. 22, n. 71, 2017. Disponível em: <http://dx.doi.org/10.1590/s1413-24782017227170>. Acesso em: 01 fev. 2018.

SOARES, José Francisco; XAVIER, Flávia Pereira. Pressupostos educacionais e estatísticos do Ideb. Educação \& Sociedade, Campinas, v. 34, n. 124, p. 903-923, jul./set. 2013.

SOUZA, Maria Celeste Reis Fernandes; CHARLOT, Bernard. Relação com o Saber na Escola em Tempo Integral. Educação \& Realidade, Porto Alegre, v. 41, n. 4, p. 1071-1093, out./dez. 2016. Disponível em: <http://dx.doi.org/10.1590/2175-623659843>. Acesso em: 01 fev. 2018.

UNESCO. Repensar a Educação. Rumo a um bem comum mundial? Brasília. UNESCO Brasil, 2016, 91 p.

UNESCO. Informe del seguimento de la EPT em el mundo. Educación para Todos em 2015? Alcanzaremos la meta? Paris. Unesco, 2007, 49 p.

WEST, Edwin George. Education vouchers in principle and practice: a survey. World Bank Research Review, v. 2, n. 2, p. 83-103, mar. 1997.

\begin{tabular}{|l|l|l|l|l|l|l} 
(C) Rev. Educ. Perspec. & Viçosa, $M G$ & v.9 & n.1 & p.104-126 & jan./abr. 2018 & eISSN 2178-8359 \\
\hline
\end{tabular}




\section{NOTAS}

${ }^{i}$ As matrículas em ACCs ocorrem por projeto, podendo, em alguns casos um mesmo aluno ser computado mais de uma vez caso participe de mais de um projeto de contraturno.

\section{SOBRE OS AUTORES}

${ }^{1}$ Eduard Angelo Bendrath: Doutor em Educação pela UNESP. Professor Adjunto da Universidade Estadual de Maringá. E-mail: bendrath@gmail.com - ORCID: http://orcid.org/0000-0003-2980-4961

${ }^{2}$ Andréia Paula Basei: E-mail: Doutoranda em Educação pela UNICAMP. Professora Assistente da Universidade Estadual de Maringá. E-mail: andreiabasei@yahoo.com.br - ORCID: http://orcid.org/0000-0002-6675-6076 